\title{
Infoentretenimiento periodístico en la cobertura de las elecciones. El caso de los debates presidenciales
}

\author{
Journalistic infotainment in election coverage. \\ The case of presidential debates
}

\author{
Martín Echeverría / echevemartin@yahoo.com.mx \\ http://orcid.org/0000-0001-6071-8725 \\ Benemérita Universidad Autónoma de Puebla, México
}

\begin{abstract}
Journalistic coverage of elections is increasingly about conflict, scandals, horse race coverage and gaffes, a phenomenon called infotainment, which is detrimental to the political content of elections, this is to say, the candidates' proposals and leader profiles. To assess the scope of these tendencies in the Mexican press, we focused our research on the coverage of presidential debates in the 2012 campaign, events with profuse political content, and undertook a content analysis of five national newspapers to measure frames related to infotainment ( $\mathrm{N}=209$ units). We found that the coverage was focused on the conflict between actors and performance assessment of the event, with little reference to the candidates' political positions and profiles. Such treatment is detrimental to the potential of civic formation of the debates, a significant feature of democracy.
\end{abstract}

Key words: infotainment, elections, content analysis, press, debates.

Resumen: La cobertura periodística de las elecciones se centra cada vez más en conflictos, escándalos, acontecimientos chuscos o cobertura de "carrera de caballos", fenómeno identificado con el término infoentretenimiento, lo que va en detrimento de la sustancia de las elecciones, esto es, las propuestas y perfiles de liderazgo de candidatos. Para determinar el alcance de estas tendencias en la prensa mexicana, tomamos como caso de estudio la cobertura de los debates presidenciales de 2012, eventos ricos en contenido político de gran utilidad cívica, y realizamos un análisis de contenido de cinco periódicos nacionales midiendo los encuadres vinculados con el infoentretenimiento ( $\mathrm{N}=290$ notas). Encontramos que la cobertura estuvo centrada en encuadres de conflicto entre actores y de evaluación de desempeño del evento, reproduciendo de manera marginal las posiciones y perfiles de los candidatos. Consecuentemente dicho tratamiento desaprovecha el potencial de formación cívica de los debates, tan significativo para la democracia.

Palabras clave: infoentretenimiento, elecciones, análisis de contenido, prensa, debates. 


\section{Introducción}

Tendencia controvertida, la proliferación de formatos y mensajes mediáticos que mezclan información sobre acontecimientos políticos con elementos de entretenimiento, denominada infoentretenimiento, ha sido objeto de numerosas críticas en relación con el potencial efecto de despolitización en las audiencias. Se ha demostrado empíricamente que la trivialización de la política mediante el énfasis de contenidos vinculados a escándalos, conflictos y estratagemas de los políticos, en detrimento de las problemáticas políticas y propuestas de campaña, además de disminuir el aprendizaje de los votantes sobre lo que está en juego en la elección, tiene la consecuencia de incrementar la desconfianza, el cinismo -entendido como un juicio a priori sobre las intenciones mezquinas de los políticos- y el bajo involucramiento de los votantes respecto a los actores en disputa, el sistema político o al régimen democrático mismo (Patterson, 1993; Capella y Jamieson, 1997; Moy et al., 2005).

En paralelo a sus efectos, destaca particularmente la capacidad de colonización del infoentretenimiento en diversos espacios del campo político: ya no es inusual la figura de un candidato presidencial que revela aspectos de su vida íntima en programas de concurso o el tratamiento agonal, dramático o deportivo de procesos legislativos o jurídicos otrora solemnes. Acontecimientos de contenido relevante para entender los procesos políticos se codifican en clave de entretenimiento, adelgazando su sustancia mediante tratamientos que proporcionan representaciones muy distintas al acontecimiento original.

Este pudiera ser el caso de los debates televisivos y la cobertura periodística que recibe. Se trata de eventos ricos en información política, que permiten evaluar la comprensión de los actores políticos acerca de las problemáticas, las idoneidad de sus propuestas, así como el perfil de los candidatos, por lo menos en términos de su desempeño como comunicador; las características de infoentretenimiento, se reporta en la literatura, pudieran traducir estas cualidades en contenidos centrados en la confrontación, la banalidad personalista o el escándalo, desaprovechando la oportunidad de amplificar el alcance de un ejercicio altamente democrático.

La investigación que aquí se presenta tiene la finalidad de constatar el alcance del fenómeno del infoentretenimiento en la cobertura periodística de los debates presidenciales de la elección mexicana de 2012, a manera de caso de estudio en relación con la cobertura de las campañas electorales en general, al tiempo que identifica los elementos que lo caracterizan. Asimismo se intenta constatar si se trata de una tendencia más o menos homogénea y por lo tanto dominante respecto a los rotativos en los cuales se presenta, los 
actores de los que se habla y el tiempo de cobertura, o más bien es un fenómeno selectivo que se presenta en relación con determinadas etapas, actores y publicaciones involucradas en la cobertura electoral.

El análisis de contenido elaborado para tal fin -realizado sobre 290 notas extraídas de cinco rotativos de circulación nacional y publicadas en los días subsecuentes al debate- identifica la presencia del infoentretenimiento mediante la búsqueda de una serie de encuadres (frames) relacionados con las características temáticas y estilísticas de dicho fenómeno; los resultados finales indican la prevalencia de dichos encuadres en la cobertura, aunque hay una importante heterogeneidad en la manifestación de los mismos.

\section{El debate televisado como objeto teórico. Conceptualización, potencialidades democráticas y encuadres de representación mediática}

En cuanto ejercicio de evaluación de desempeño, el presente trabajo establece una estrategia teórica que contrasta el fenómeno del debate televisado, su naturaleza comunicativa, supuestos normativos y consecuencias empíricas, con los patrones de tratamiento periodístico a los que éste es sometido. El contraste entre el objeto factual y su representación periodística supera una descripción mediática per se y posibilita hacer observaciones más precisas del comportamiento de este último.

\section{Objeto, normativa y efectos de los debates televisivos}

Como objeto de estudio, los debates televisados se conciben como arenas o situaciones de interacción con carácter ritual, donde los discursos políticos se confrontan, difunden y evalúan públicamente bajo reglas específicas por parte de actores que buscan influir en la conducta de los votantes, mediante estrategias teatralizadas de autopresentación. En ese marco se formaliza, estructura, controla y encauza el conflicto político, pero dentro de límites de civilidad (Bélanger, 1998; Gosselin, 1998; Kraus y Davis, 1981). El debate se concibe así como un modelo a pequeña escala de la democracia pensada como un marco institucional para el tratamiento de conflictos desde la comunicación y el diálogo (Dader, 1998).

Esta conceptualización específica tiene implicaciones respecto a la manera como los medios informativos deciden reportar el acontecimiento, dado que entraña la escenificación pública de una confrontación política que está sujeta a reglas de civilidad verbal y diálogo ordenado (aspecto al cual regresamos más adelante). 
En un lectura a nivel de sistema político, la sola organización de los debates y su amplificación mediática tiene implicaciones democráticas per se que suponen un aporte a la calidad del voto que emite el electorado: se les proporciona a los votantes la misma información electoral, lo cual los pone en una posición de equidad (Benoit y Sheafer, 2006); hay un contacto más directo y prolongado de los votantes con los candidatos, sin una mediación editorial proclive al sesgo (Benoit y Brazeal, 2002); la tendencia regular de los votantes a exponerse selectivamente a los mensajes de los candidatos afines se rompe en virtud de la exposición comparativa y simultánea que tienen a los distintos candidatos, de manera que aquellos aprenden forzosamente de las propuestas de los aspirantes no afines y elevan o racionalizan los contrastes entre los mismos.

Asimismo, la información política ahí vertida alcanza a través de los debates un nivel elevado de audiencia - prácticamente imposible de conseguir para otros formatos de comunicación política-, así como una extensa y relativamente prolongada cobertura mediática antes y después del evento, lo cual hace muy probable que los debates capturen la atención de ciudadanos poco politizados y atentos a las campañas, que obtienen así un conocimiento mínimo para acudir a votar (McKinney y Carlin, 2004).

La investigación empírica sobre los efectos de los debates constata por un lado una serie de efectos conductuales moderados en los votantes, tales como incrementar la motivación para ir a votar, activar la búsqueda de mayor información de la campaña e intensificar la discusión con pares (Wyatt, 2000); no obstante, el principal efecto de dichos eventos radica en incrementar el conocimiento de los votantes acerca de lo que está en juego en la campaña. La duración de dos horas promedio implica una exposición prolongada a una cantidad voluminosa, relativamente sofisticada de información, mediante la cual los ciudadanos adquieren conocimiento de las problemáticas públicas, los temas y posiciones específicas de cada candidato y están, en consecuencia, en mejores condiciones para evaluarlas (Benoit et al., 1998; Cho, 2009; Drew y Weaver, 2006; Jarman, 2005).

Asimismo, a través de la lectura "en directo" del desenvolvimiento personal de los candidatos, los votantes se forman una impresión más compleja de su carácter y posición en la contienda, de modo que los evalúan con mejores elementos y eventualmente matizan o modifican la percepción que tenían de ellos (Cho, 2009; Jarman, 2005).

En un espacio mediático dominado por formatos de comunicación política cada vez más pobres tales como las noticias o los spots (Juárez y Echeverría, 2009), los debates televisados se pueden caracterizar desde el 
punto de vista normativo como fuentes de información e instituciones con un potencial importante para generar racionalidad, deliberación y decisión electoral informada, contribuyendo así a elevar la calidad de los procesos democráticos.

\section{Tratamiento infoentretenido de los debates televisados. Encuadres y evidencia empirica de cobertura}

La cobertura periodística de los debates televisados es relevante por partida doble: en primera instancia, constituye un dispositivo que expone al debate a las personas que no lo presenciaron, y, en segundo lugar, puede llevar a los espectadores que sí lo hicieron a reinterpretarlos en otras direcciones (Benoit y Currie, 2001). Hipotéticamente, una orientación normativa de servicio público llevaría a los medios informativos a cubrir el debate de una manera tal que permitiera amplificar cuantitativamente, en términos de audiencia, el alcance de varios de los supuestos y efectos ventajosos enumerados con anterioridad, en atención a los principios relacionados con la función cívica del periodismo, su propósito (normativo) de hacer entender la realidad social (McQuail, 1998).

No obstante, en lustros recientes ha cobrado relevancia el fenómeno del infoentretenimiento ${ }^{1}$ como patrón de tratamiento periodístico acerca de los acontecimientos políticos. Para efectos de este trabajo y ante una definición aún muy abarcadora del término - puesto que involucra diversos temas, estilos y formatos en una multiplicidad de canales de comunicación pública-, definimos su especificidad en relación con el periodismo político, esclareciendo los aspectos asociados al fenómeno tanto en los niveles macro, particularmente de naturaleza económica, y micro, al interior de los mensajes periodísticos, mismos que serán de utilidad para arribar a una conceptualización razonada.

Por lo que se refiere a la dimensión macro del fenómeno, es patente la propensión de las empresas periodísticas a abarcar mercados de audiencias más amplios que su habitual público de élite, ya predispuesto al consumo de

1 La perspectiva aquí implementada es deudora de una tradición anglosajona parecida pero distinguible de los desarrollos relativos a la espectacularización de la política, corriente de sociología y filosofía política crítica que cobró auge en los años noventa (Debray, 1993; Thompson, 1998; Edelman, 1991) y permanece vigente hasta hoy en día (Aruguete, 2013; Serpa, 2013), centrada en aquellos despliegues mediáticos de los actores políticos que emplean formas de escenificación visiva, personalizante y teatral, con una carga fuerte de populismo. El concepto de infoentretenimiento, en contraste, se considera más amplio, pues involucra modalidades más sutiles y generales de entretenimiento en productos de ficción, periodismo o redes sociales (Baym, 2008; Berrocal et al., 2012). 
información política. En función de ello, se abocan, por un lado, a elaborar mensajes que persiguen de manera primordial el objetivo de capturar, cautivar y retener la atención de las audiencias mediante un énfasis en los aspectos estilísticos, atrayentes y emotivos de los mensajes; ello es funcional a los intereses mercantiles de los medios, en tanto que la atención es el bien primordial (y escaso) que los medios venden a sus anunciantes (McQuail, 2001).

Por otro lado, efectúan lo que Gans llama una "popularización” de la información periodística; esto es, "la adaptación de un producto cultural inicialmente creado para una cultura de alto gusto" (en este caso, la prensa de referencia con información política sustanciosa) al consumo y uso de una cultura correspondiente a una audiencia de menor estatus que la original" (Gans, 2009: 19).

Dicha adaptación suele involucrar fundamentalmente una operación de simplificación de contenidos, a lo que le siguen otras alteraciones estilísticas como el reemplazo del lenguaje técnico por el coloquial, o de imágenes o formas abstractas con imágenes naturales o populares. Así, los medios informativos otrora dirigidos a audiencias de alto nivel cultural popularizan las noticias, incluidas las políticas, admitiendo códigos de la cultura popular que son por lo común cercanas al entretenimiento.

En su nivel micro, relativo a las características de los mensajes, este fenómeno se puede comprender como la elaboración de noticias políticas bajo una lógica mediática, una gramática "evocativa, encapsulada, altamente temática, familiar con las audiencias y fácil de usar” (Altheide, 2004: 294), que prescribe la estructuración de mensajes con un lenguaje y ritmo fragmentario, simplificado y efectista para comunicarse con las audiencias. Dicha gramática establece, a su vez, "los códigos (que los periodistas utilizan) para definir, seleccionar, organizar, presentar y reconocer información" (Altheide, 2004: 294), de manera que estructura casi por completo el proceso de producción noticiosa.

Podemos condensar lo dicho hasta aquí conceptualizando al infoentretenimiento político como una operación de énfasis en las noticias acerca del campo político, de elementos formales, estilísticos o temáticos capaces de hacer más accesibles y atrayentes los contenidos políticos a audiencias en principio no interesadas o familiarizadas con el campo de la política; dicho énfasis emplea un conjunto de códigos simplificadores, fragmentadores y efectistas que, a la base del proceso de producción mediática, definen, seleccionan, organizan y presentan noticias susceptibles de entretener, la principal estrategia para captar y mantener la atención de las audiencias. 
Ahora bien, una manera adecuada de categorizar las expresiones periodísticas relacionadas con el infoentretenimiento es mediante el recurso teórico metodológico del encuadre, ${ }^{2}$ que ayuda a describir en qué consiste su tratamiento. Respecto a la cobertura de las elecciones, la literatura internacional reporta, por un lado, la prevalencia de un macro encuadre temático tradicional, centrado en la sustancia de la política y orientado al desempeño democrático de los medios; éste se refiere a problemas y soluciones de política pública, discusión de los temas públicos (causas, soluciones y medidas), posiciones de los políticos acerca de los mismos, descripciones de legislación o programas de gobierno, e implicaciones de las mismas (Berganza, 2008; Brants y Neijens, 1998; Lawrence, 2000).

En contraste, se pone de manifiesto la creciente presencia de un macro encuadre de contienda, que para la presente teorización constituye la expresión manifiesta del infoentretenimiento. Se trata de una manera de entender y explicar la política como una confrontación, en la cual los políticos compiten por ventajas y están interesados en su victoria (Jensen, 2012). Este encuadre general se descompone en al menos cinco encuadres particulares -conflicto, estrategia, juego, dramatización y personalización-, que especifican temática y estilísticamente a aquél.

El encuadre de conflicto caracteriza a la política como un escenario polarizado, en el cual ocurren fricciones y controversias entre individuos (en solitario), grupos e instituciones, con poca atención a los temas que están en juego y la sustancia de los mismos. Cercano a dicho encuadre está el estratégico, en el cual los reporteros interpretan los "verdaderos" motivos e intenciones que subyacen a las acciones o propuestas de los actores, así como las tácticas necesarias para que éstos ganen posiciones.

Por su parte, el encuadre de juego introduce como característica principal el uso del lenguaje y la narrativa de los deportes, de modo que comparte con el anterior los atributos de una competencia férrea, un carácter agonal y confrontativo. Éste se expresa comúnmente con la metáfora de la "carrera de caballos", en virtud del cual se reporta mediante encuestas quién va adelante

2 La conceptualización aquí utilizada es aplicable específicamente en los encuadres periodísticos, que pueden entenderse como esquemas o principios de tratamiento de la información que se manifiestan en la selección y exclusión de ciertos observables, énfasis de unos sobre otros y la organización de los mismos en un discurso que los presenta en función de un determinado significado (Igartua et al., 2007; Muñiz, 2011; Reese, 2010; Zhang, 2000). La generación de encuadres por parte de los periodistas, a manera de guías internalizadas de procesamiento de información (Klein, 2000), está gobernada por constricciones institucionales, rutinas, prácticas o ideologías que les permiten discriminar qué temas seleccionar y qué énfasis y significados imprimirles (Sádaba et al., 2007). 
o detrás en la "carrera" por cruzar la recta final (Anikin, 2009; Jensen, 2012; Johnson-Cartee, 2005).

El encuadre dramático, por su parte, incluye historias de interés humano que expresan el "rostro humano" o "ángulo emocional" de los eventos, temas o problemas relacionados con la campaña, así como acontecimientos chuscos de los candidatos; a éste pertenece el fenómeno de la personalización, en el doble sentido del énfasis en personajes e historias de vida que generan una identificación en la audiencia, o bien la caracterización de los políticos como individuos, con atributos personales y vidas privadas antes que como representantes de intereses colectivos.

La implementación de estos encuadres de contienda traduce la tendencia de infoentretenimiento en esquemas de producción y contenido periodísticos, de manera antagónica al encuadre político tradicional, pues pretende comunicar la dimensión excitante y entretenida de los procesos políticos en lugar de la sustancia de lo que está en juego. En el caso de los debates, una cobertura que le da un valor de entretenimiento a las notas periodísticas acerca de los mismos atenúa las ventajas mencionadas en el apartado anterior, desfavoreciendo su importante función cívica.

Es cierto que los candidatos han proferido varias revelaciones escandalosas e invectivas durante los escasos ocho debates que se han llevado a cabo en las últimas cuatro elecciones presidenciales en México, un material que ha sido estudiado por las disciplinas lingüístico cognitivas; no obstante, los análisis de contenido panorámicos que se han realizado encuentran que respecto al grueso del debate, la confrontación es menor: por ejemplo, el análisis funcional de los debates de 2006 observa que se usó en promedio 6.21 aclamaciones (propuestas de política pública) por 2.08 ataques (Téllez et al., 2010). Otro trabajo halla que la proporción de enunciaciones referidas a propuestas en los dos debates presidenciales de 2012 fue cinco veces mayor a las de ataque (Echeverría y Chong, 2013). En general, los análisis empíricos de los debates constatan que éstos se han llevado a cabo en buena medida con civilidad.

No obstante, un trabajo más demuestra que las notas publicadas al día siguiente de los debates de 2012 en periódicos de referencia manifiestan una proporción equiparable entre propuestas y ataques (Echeverría y Millet, 2013), de manera que se comunicó en los rotativos la impresión de un debate -en los términos aquí expuestos- mitad sustancioso y mitad confrontativo, una representación que desvirtúa su desempeño cívico con todo lo que ello implica. La replicación de estos hallazgos extendiendo el radio de análisis a la cobertura total del debate es la finalidad del siguiente ejercicio empírico. 


\section{Metodología}

La estrategia metodológica de este trabajo tiene como finalidad constatar el grado de penetración de una cobertura infoentretenida en la prensa nacional, mediante el análisis de contenido aplicado a la cobertura de acontecimientos altamente visibles y políticamente significativos, como es el caso de los debates televisivos, que de suyo revisten una sustancia temática considerable, aunque la manifestación esporádica de confrontaciones y su naturaleza de conflicto verbal estructurado los hacen susceptibles de ser encuadrados bajo el esquema de contienda, concreción simbólica de las tendencias de infoentretenimiento. Así, el debate se configura como un caso de estudio idóneo para la finalidad mencionada.

Más allá de su peso cualitativo en la opinión pública y accesibilidad en cuanto a archivo histórico, la elección de la prensa caracterizada como "seria" o "generalista", por oposición a la prensa "amarilla", sensacionalista o popular, radica también en que es el medio aparentemente menos poroso a las tendencias de infoentretenimiento, a diferencia de la televisión en que éstas han estado presentes con intensidad desde hace varios lustros; la penetración de dichas tendencias en la prensa de referencia sería un indicador altamente significativo del alcance del fenómeno en el sistema mediático mexicano.

La muestra consistió en un análisis del archivo digital de los diarios Reforma, La Jornada, El Universal, La Crónica, Milenio y Excélsior; éstos se seleccionaron por tratarse de rotativos de alto tiraje, distribución nacional, considerados como "prensa seria", de prestigio o de referencia, de acuerdo al Padrón Nacional de Medios Impresos de la Secretaría de Gobernación mexicana (SEGOB, 2013). Se revisó toda la cobertura que generó cada debate durante los días subsecuentes al mismo, nueve fechas en el caso del primer debate (del 7 al 15 de mayo) y cinco en el caso del segundo (del 10 al 14 de junio). Las notas fueron seleccionadas de acuerdo a si reportaban o juzgaban lo acontecido en los debates o bien discutían algún aspecto del desempeño o consecuencias de los mismos, haciendo un total de 290 de ellas.

Respecto al libro de códigos, se utilizó el desarrollado para el análisis de la cobertura de las elecciones presidenciales de 2012 (Echeverría y Meyer 2015), que se construyó combinando de manera inductiva un análisis cualitativo de comparación constante y la definición de los encuadres reportados por la literatura internacional (Alberg et al., 2011; Capella y Jamieson, 1997; Klein, 2000; Lawrence, 2000; Semetko y Valkenburg, 2000; Strömbäck y Luengo, 2008). 
A partir de dicho ejercicio emergieron, se confirmaron y ajustaron dos encuadres macro o generales (denominados para este ejercicio como de "contienda" y "político"), seis encuadres particulares ("drama”, "juego" y "estrategia”, correspondiente al primer macro encuadre y "temas políticas e ideas", "proceso político" y "liderazgo político"3 para el segundo) así como 23 subencuadres desprendidos de estos seis. La confiabilidad Kappa de tal protocolo se cifró en .831 para los macro encuadres y .739 para los encuadres, considerados aceptables para un ejercicio exploratorio como el presente (aunque los subencuadres no alcanzaron un parámetro satisfactorio de confiabilidad).

Se utilizó el criterio de un solo encuadre dominante por nota; aunque en la literatura se admite que puede haber varios encuadres en una sola nota, dividir el contenido de manera tan fina implicaría identificar múltiples encuadres que dificultarían la observación global (Binderkrantz y GreenPedersen, 2009). Por su parte, la unidad de análisis dentro de la nota fue el encabezado, por razones prácticas pero también por razones teóricas, puesto que éste constituye el dispositivo más poderoso de encuadramiento de la nota (Van Dijk, 1990), capaz de activar conceptos en el lector e influir así la lectura del resto de la misma (Klein, 2000; Tewksbury et al., 2000).

Por su parte, los debates de la campaña de 2012 se efectuaron entre los candidatos Enrique Peña Nieto del Partido Revolucionario Institucional, ex gobernador del Estado de México, Josefina Vázquez Mota del Partido Acción Nacional, ex secretaria de Desarrollo Social y de Educación y diputada federal, Andrés Manuel López Obrador del Partido de la Revolución Democrática, ex jefe de gobierno del Distrito Federal y previo candidato a la presidencia, así como Gabriel Quadri de la Torre del partido Nueva Alianza, funcionario, consultor y empresario del medio ambiente. El primer debate se llevó a cabo el 6 de mayo y se transmitió por los canales 5 de Televisa y 40 de TV Azteca (que no tiene cobertura nacional), logrando una audiencia de 10.4 puntos de rating en la primera cadena (Torres, 2012).

El segundo debate presidencial se transmitió el 10 de junio por los canales 2 de Televisa y 13 de TV Azteca, que junto con otros permisionarios y

3 A diferencia de los primeros encuadres de contienda, estos últimos no fueron descritos en el marco teórico de este trabajo, por lo que proporcionamos una definición mínima. El encuadre de "temas, políticas e ideas" se enfoca en la sustancia de los temas y soluciones de política pública, posiciones personales y consecuencias de las mismas; el encuadre de "proceso político" describe los procesos formales, acontecimientos y eventos inherentes a la campaña, que comprende los eventos así como los procesos judiciales, organización y financiamiento de la campaña; y el encuadre "liderazgo político" caracteriza, como su nombre lo dice, el liderazgo del candidato en términos de ideología, carácter y antecedentes biográficos. 
concesionarios enlazados, alcanzó una cobertura potencial del $92.5 \%$ de los hogares a nivel nacional. Combinado ello con la cercanía de los comicios, la audiencia de tal evento fue de 22.6 puntos de rating, el más alto de la historia para un debate presidencial (Torres, 2012). De acuerdo con las encuestas, el $60 \%$ de los ciudadanos vio el debate en vivo o en repetición y platicó sobre éste (Torres, 2012); mientras que para el 55\% de los electores fue importante que los debates hayan sido televisados (Flores-Villar, 2012).

\section{Hallazgos}

Los resultados del análisis de contenido exponen en primera instancia las diferencias respecto al volumen de cobertura otorgado a cada debate; los encuadres dominantes en la cobertura; los aspectos específicos en los que los mismos son prevalecientes, en términos de actores y momentos; y el grado de homogeneidad de estas tendencias en los rotativos de la muestra.

Un primer hallazgo refiere a la duración diferenciada de la cobertura entre el primer y segundo debate; ésta revela la dinámica de tematización en cuanto al énfasis otorgado por los rotativos, independientemente de la relevancia del acontecimiento mismo. A este respecto, el contraste entre ambos debates es muy significativo. Si bien ambas coberturas son extensas al primer y segundo día del acontecimiento, para luego disminuir y desaparecer paulatinamente -un tratamiento típico-, el primer debate reproduce 82 notas el primer día y 81 , el segundo día, en una cobertura total de 9 días $(19,17,11,7,3,6$ y 3 notas cada día a partir del tercero); mientras que el segundo debate genera 46 notas el primer día y 12, el segundo día, desplegado en una cobertura de 4 días, con sólo dos y una nota en los últimos.

La observación general es que aunque ambos debates concentran poco más de dos terceras partes de las notas en el primer o segundo día, para luego disminuir y desaparecer, el segundo debate tiene menos visibilidad y desaparece más rápido de la esfera mediática. Esta particularidad será puesta de relieve al interpretar los datos en relación con los niveles de rating de ambos acontecimientos.

Respecto a los encuadres, en términos globales el macro encuadre de contienda duplica en frecuencia (66\%) al macro encuadre de política (33\%) (véase Tabla $1^{4}$ ). Es de llamar la atención que tanto el encuadre de temas (3\%) como el de liderazgo (1\%) son muy poco visibles. En cambio, el encuadre de proceso político acapara la tercera parte de las notas (29\%); en particular 4 Las tablas y las gráficas se encuentran en el Anexo, al final del presente artículo (Nota del editor). 
destaca el subencuadre "organización, procedimientos y regulación formal" con cerca de una cuarta parte de las mismas (23\%); éste trata principalmente de evaluaciones positivas o negativas acerca de la organización y desempeño del debate, su cobertura de transmisión, así como las medidas correctivas en vistas al segundo debate, ello por parte de autoridades electorales, actores políticos y miembros destacados de la sociedad civil.

Del lado del macro encuadre contienda, que operacionaliza el infoentretenimiento, el encuadre de estrategia es el más frecuente (32\%) gracias al énfasis de los subencuadres de conflicto, tanto dentro del campo político, entre los actores formales (20\%), como fuera de él (6\%), entre actores de la sociedad civil.

En segunda instancia sobresale el encuadre de juego (23\%), con caracterizaciones del debate en términos de ganar y perder (9\%), de deporte, guerra y competencia (6\%) o bien de marcadores (7\%), es decir, de expresiones de la opinión pública en forma de mediciones en tiempo real del debate, encuestas de intención de voto, grupos focales o conversación colectiva en las redes sociales virtuales, con el acento en develar quién "ganó" o "perdió" los debates.

El encuadre de drama, finalmente, es poco recurrente (10\%) y destaca en éste el acontecimiento chusco de la edecán del primer debate (8\%), cuyo atuendo en combinación con sus antecedentes como modelo de revista para caballeros causó reacciones vehementes en la cobertura periodística.

Existen, por otro lado, importantes discrepancias en los encuadres enfatizados en ambos debates en función, probablemente, de la diferencia en la cobertura que suscitó cada uno de ellos, dado que el primero recibió casi cuatro veces más cobertura que el segundo.

El segundo debate estuvo mucho más centrado que el primero en el macro encuadre de contienda que en el de política ( 82 y $18 \%$, respectivamente en el de contienda; 38 y $62 \%$, en el de política). Éste se enfocó menos en la evaluación del formato del debate, aspecto que se redujo del $28 \%$ en el primer debate al 3\% en el segundo. El subencuadre de conflicto incrementó al encontrarse en casi el $40 \%$ de la cobertura, en contraste con el $21 \%$ del primer debate. El encuadre de juego también incrementó, de la quinta parte en el primer debate $(21 \%)$ a la tercera parte en el segundo (31\%), en particular respecto al uso de marcadores (de 6 a 13\%) y un lenguaje de deporte, guerra o competencia (de 5 a 9\%). En suma, posiblemente a raíz de una menor cobertura, el segundo debate estuvo significativamente más enfocado en encuadres de infoentretenimiento.

Un siguiente objetivo de investigación consiste en indagar la medida en que los encuadres son aplicados a la cobertura en general, lo cual convierte su 
aplicación en homogénea, o bien centrada en ciertos elementos tales como los tiempos y los actores, lo que la hace selectiva. Esto último se contesta mediante la Tabla 2, que por parsimonia asocia solamente los macro encuadres políticos y de contienda con los actores. Utilizando el parámetro de rango, podemos observar que los distintos tipos de actores están más o menos asociados con un encuadre u otro. Los actores partidistas (miembros de partidos políticos desde diferentes jerarquías, así como los equipos de campaña) presentan un equilibrio mayor entre los encuadres de contienda y los políticos. Salvo los miembros y el equipo de campaña del PAN y del PRI, cuyas notas se elaboran con el macro encuadre de contienda principalmente, el resto de estos actores manifiesta un equilibrio entre ambos $(\mathrm{R}=18)$.

El grupo de actores de la sociedad civil está más desequilibrado que el anterior $(\mathrm{R}=38)$. Particularmente abundan las representaciones de los ciudadanos a través de las encuestas, así como de juicios de expertos, cuyas discursos se encuadran a manera de pronunciamientos del tipo ganar o perder, antes que evaluaciones técnicas; de este modo, este grupo en su conjunto exhibe un desequilibrio a favor del macro encuadre contienda, que triplica al de política ( 73 y $27 \%$, respectivamente).

En los actores políticos se finca un desequilibrio desproporcional entre el macro encuadre de política (11\%) y el de contienda (89\%) $(\mathrm{R}=111)$. Esta proporción y el rango es similar en los distintos actores, aunque se acentúa ligeramente en el caso de Vásquez Mota y Quadri de la Torre (32 y 36\% de macro encuadre contienda, respectivamente).

En contraste, la autoridad electoral, que comprende al Instituto Federal Electoral, sus consejeros y el tribunal electoral, son encuadrados principalmente respecto a los procesos políticos en un $76 \%$, frente al $24 \%$ en clave de contienda.

En función de estos datos es posible afirmar que la aplicación de un encuadre es altamente dependiente del tipo de actor de que se trata, es decir, es selectiva. Una prueba estadística de correlación aplicada a las variables de actor y macro encuadre, $\mathrm{c}^{2}(3, \mathrm{~N}=290)=74.77, \mathrm{p}=.000$, confirma este aserto, que se presenta además en una magnitud muy significativa (V de Cramer, .509). No obstante, dentro de esos grupos el patrón es más homogéneo en el caso de los candidatos, cuyos acontecimientos son encuadrados de manera desproporcionada como una contienda más que una elección política.

El despliegue de los encuadres en el tiempo y, por ende, su distribución constituye otra dimensión de énfasis conferido a los mismos: aun cuando las frecuencias simples establezcan una jerarquía implícita, es significativo también el dato de si tal o cual encuadre fue sostenido a lo largo de la cobertura 
o más bien fue usado con intensidad durante unos pocos días para después desaparecer. Para esclarecer este indicador, tomamos los cuatro subencuadres más frecuentes, "organización y regulación formal", que corresponde al encuadre de proceso, así como los de "conflicto", "expresiones de ganar o perder" y "marcadores de opinión pública”, correspondientes al macro encuadre de contienda y los desplegamos en el tiempo (véase Gráfico 1).

La observación general es que la visibilidad de los distintos encuadres difiere a lo largo del tiempo. Los tres encuadres de contienda tienen una manifestación muy enfática en los dos días posteriores al debate, pero disminuyen drásticamente al segundo o tercer día, y se extinguen con rapidez. El encuadre de "organización y procesos formales" alrededor del debate cede su lugar en el primer día a las notas de contienda, pero recupera brío hacia el segundo y se sostiene paulatinamente durante los tres días siguientes, hasta menguar a partir del cuarto.

La cobertura del segundo debate tiene un comportamiento distinto, dado su despliegue breve en el tiempo, la reducida frecuencia de encuadres de política y la predominancia de encuadres de contienda que tienen el mismo comportamiento que en el primer debate. Por ejemplo, el encuadre de conflicto es el más frecuente con 17 notas el primer día, pero se reduce drásticamente el segundo día con cinco notas. Lo mismo sucede con el subencuadre de marcadores, que pasa de siete notas a una al día siguiente. Esto significa que la primera caracterización del debate por parte de los medios es de una contienda, pero después se centra en su carácter de proceso político regular, incluso por un tiempo relativamente prolongado.

Finalmente, nos preguntamos en qué medida la aplicación de encuadres es una tendencia homogénea entre los diversos rotativos, de modo que ésta pudiera constituir de lleno un atributo de la prensa mexicana de referencia. Como observamos en el Gráfico 2, existen diferencias en el tratamiento que los diversos rotativos le dan a los debates, aunque no parecen significativas. Ningún rotativo le da un espacio importante a los temas y problemas del debate o abunda en el liderazgo de los candidatos. La inclinación por el drama (personalización, acontecimientos chuscos, etc.) tiene variaciones, aunque su prevalencia está en el rango de 8 a 13\%, salvo el caso de La Jornada, que no tiene nota alguna con ese enfoque.

Los encuadres de proceso político, juego y estrategia son predominantes para todos los rotativos y tienen una proporción similar entre sí, aunque los énfasis son diferentes. Por ejemplo, La Crónica encuadra el 43\% de sus notas como un proceso político, mientras que Excélsior lo hace sólo en el $22 \%$ de las mismas. De igual manera, el Reforma le da al 19\% de sus notas 
un encuadre de juego, mientras que El Universal lo hace el $31 \%$ de las veces. En suma, y verificando los datos con la prueba estadística de Chi-cuadrado, c $(25, \mathrm{~N}=290)=25.58, \mathrm{p}=.43$, no parece haber una relación general entre los medios y los encuadres del debate, esto es, existe un tratamiento heterogéneo del acontecimiento y en ocasiones casi idiosincrásico.

\section{Discusión y conclusiones}

A manera de caso de estudio, la cobertura periodística de los debates presidenciales funciona como un indicador relevante de las inclinaciones periodísticas en el tratamiento de la realidad política. Los datos expuestos permiten desahogar la inquietud principal acerca de la presencia y alcance de los encuadres de infoentretenimiento en la cobertura de las elecciones.

En primer lugar se pone de relieve la significativa diferencia entre el volumen de cobertura del primer y segundo debate, en contraste con los niveles de rating de ambos, en donde el segundo fue muy superior. Constatamos aquí la manera en que el valor de noticiabilidad del primer debate, un "gran evento" mediático altamente esperado por políticos y ciudadanos, trastorna a favor de uno sólo la relevancia equiparable de los dos.

Respecto a los resultados de la medición de encuadres, el evento del debate parece ser más importante para la prensa en virtud de lo excitante que puede llegar a ser o su relevancia sociopolítica per se, sin reparar en el contenido político que ahí se vierte. Ello se sustenta en virtud de los encuadres procesual y de estrategia que se enfatizan: al encuadrar cerca de la cuarta parte de las notas como acontecimientos centrados en la organización, procedimientos y regulación del debate, se revela una caracterización del debate como "evento mediático" significativo por su carácter masivo y de relevancia institucional.

Por el lado del encuadre de contienda, al parecer la naturaleza del debate como conflicto verbal normado es aprovechada por la prensa para enfatizar el conflicto o roces que en efecto surgieron ahí, aunque de manera esporádica, o bien su lectura en términos de posiciones políticas dentro de una "carrera por la presidencia”, los dos subencuadres más recurrentes. Aunado al evento chusco de la edecán en el primer debate, no sólo el encuadre de contienda en global duplica en frecuencia al temático, por lo cual el debate se torna en la prensa en una confrontación individualista por el poder, sino que prácticamente se invisibilizan los aspectos relativos a temas, políticas e ideas, así como lo relacionado con el liderazgo político de los candidatos, elementos de sustancia política que mayor aprendizaje suscitan los debates en las audiencias, de acuerdo con la literatura. 
La preferencia por la dimensión de contienda de los debates se ilustra muy bien en su temporalidad de cobertura: los días inmediatamente posteriores a los mismos, cuando hay una mayor expectación por la cobertura periodística, registran una presencia predominante de notas con este encuadre. En los días subsecuentes, cuando la atención por el debate se diluye, es cuando se enfatiza el encuadre temático - particularmente la evaluación oficial del proceso-y se desenfatizan aceleradamente los encuadres de contienda. Además de su elevada frecuencia neta, se corrobora la pretensión de darle mayor visibilidad al tratamiento infoentretenido de los encuadres, colocándolo en tiempos de mayor captación de lectores.

$\mathrm{Al}$ detallar la naturaleza de los encuadres se encuentra que aquellos vinculados con el infoentretenimiento son más claramente aplicados en los candidatos, protagonistas de la elección en tanto contienda y los ciudadanos en cuanto árbitros legitimados para emitir veredictos de "victoria" o "derrota" de los mismos. Las autoridades electorales están parcialmente alejadas de tal caracterización, al ser los voceros del debate como evento oficial y legal, así como los actores partidistas en tanto gestores o copartícipes de su organización.

Por otro lado, la tendencia de infoentretenimiento es heterogénea en los distintos rotativos en relación con el énfasis que cada uno hace en ciertos encuadres. Lo que comparten es la reproducción marginal de los temas de campaña y perfiles de liderazgo, aspectos sustanciales de los debates, así como una atención importante al debate como proceso político oficial y como conflicto espectacular.

Estos últimos tres datos apuntan a una tendencia heterogénea de penetración del infoentretenimiento en la cobertura de las elecciones, al menos en lo que respecta a los debates televisados. Los encuadres de contienda se manifiestan con énfasis en ciertos tiempos, se vinculan con ciertos actores y son destacados en mayor medida por ciertos rotativos, con lo que se descarta la hipótesis de la penetración de este tratamiento de manera general y avasalladora.

Dicho comportamiento pudiera vincularse con una tensión al interior de los rotativos entre una vocación de servicio público, que apunta a reproducir y con ello magnificar la sustancia temática de los debates y una presión comercial que identifica la oportunidad de alcanzar a un mercado despolitizado que tal vez no presenció el debate, pero que pudiera acudir a sus páginas para enterarse de él, dada la enorme expectación que genera, siempre y cuando la información presente un tratamiento infoentretenido capaz de captar su atención.

En conclusión, y en dirección a una evaluación de desempeño, la cobertura periodística de los debates no amplifica el conocimiento que se vierte en 
los mismos, tanto acerca de los temas que están en juego durante la elección o el perfil de los candidatos, intensifica en lugar de acortar la desigualdad de conocimiento entre aquellos ciudadanos que presenciaron el debate y aquellos que se expusieron a él a través de su cobertura, y en suma no contribuye a la racionalidad y deliberación que éstos posibilitan.

\section{Referencias}

Alberg, Toril et al. (2011), "The framing of politics as a strategy and game: a review of concepts, operationalizations and key findings", en Journalism, núm. 2, vol. 13, Estados Unidos: Sage.

Altheide, David (2004), "Media logic and political communication", en Political Communication, núm. 3, vol. 21, Estados Unidos: Routledge.

Anikin, Evgeny (2009), "The 2008 US presidential election in the mirror of sports metaphor (in the French Press)", en Respectus Pbilologicus, núm. 27, vol. 1, Polonia: Vilnius University.

Aruguete, Natalia (2013), "La narración del espectáculo político: pensar la relación entre sistema de medios y poder político", en Austral Comunicación, núm. 2, vol. 2, Argentina: Universidad Austral.

Baym, Geoffrey (2008), "Infotainment", en Donsbach, Wolfgang [comp.], The International Encyclopedia of Communication, Inglaterra: Blackwell Publishing,

Bélanger, Yré (1998), "La comunicación política, o el juego del teatro y de las arenas", en Gilles, Gauthier, Yré, Gosselin y Jean Mouchon [comps.], Comunicación y politica, España: Gedisa.

Benoit, William y Currie, Heather (2001), "Inaccuracies in media coverage of the 1996 and 2000 presidential debates", en Argumentation and Advocacy, núm. 38, Estados Unidos: American Forensic Association.

Benoit, William et al. (1998), "Effects of presidential debate watching and ideology on attitudes and knowledge", Argumentation and Advocacy, año 34, núm. 4, Estados Unidos: American Forensic Association.

Benoit, William y Brazeal, LeAnn (2002), "A functional analysis of the 1988 Bush-Dukakis presidential debates", en Argumentation and Advocacy, núm. 4, vol. 38, Estados Unidos: American Forensic Association.

Benoit, William y Sheafer, Tamir (2006), "Functional theory and political discourse: televised debates in Israel and the United States", en Journalism and Mass Communication Quarterly, núm. 2, vol. 83, Estados Unidos: Sage.

Berganza, María-Rosa (2008), "Medios de comunicación, espiral del cinismo y desconfianza política. Estudio de caso de la cobertura mediática de los comicios electorales europeos", en Zer, núm. 25, vol. 13, España: Universidad del País Vasco.

Berrocal, Salomé et al. (2012), "Una aproximación al estudio del infoentretenimiento en Internet: origen, desarrollo y perspectivas futuras", en adComunica. Revista de Estrategias, Tendencias e Innovación en Comunicación, núm. 4, España: Facultat de Ciències Humanes i Socials, Universitat Jaume I. 
Binderkrantz, Anne y Green-Pedersen, Christoffer (2009), "Policy or processes in focus?", en The International Journal of Press/Politics, vol. 14, núm. 2, Estados Unidos: Harvard University Press.

Brants, Kees y Neijens, Peter (1998), “The Infotainment of Politics”, en Political Communication, núm. 2, vol. 15, Estados Unidos: Routledge.

Capella, Joseph y Jamieson, Kathleen (1997), Spiral of cynicism: the press and the public good, Inglaterra: Oxford University Press.

Cho, J. (2009), "Disentangling media effects from debate effects: the presentation mode of televised debates and viewer decision making", en Journalism and Mass Communication Quaterly, núm. 2, vol. 86, Estados Unidos: Sage.

Dader, Jose-Luis (1998), Tratado de comunicación politica, España: Edición propia.

Debray, Regis (1993), L'État séducteur, Les révolutions mediologiques du pouvoir, París: Editions Gallimard.

Drew, Dan y Weaver, David (2006), "Voter learning in the 2004 presidential election: did the media matter?", en Journalism and Mass Communication Quarterly, núm. 1, vol. 83, Estados Unidos: Sage.

Echeverría, Martín y Meyer, José (2015), “El infoentretenimiento en la cobertura periodística de las elecciones. Un abordaje desde la teoría del encuadre”, en Daniel Ivoskus, Angélica Mendieta y Raffaeli Marina [comps.], Sexto sentido para gobernar. Politica y comunicación, México: BUAP, Paralelo Cero.

Echeverría, Martín y Chong, Blanca (2013), "Debates presidenciales y calidad de la democracia. Análisis empírico normativo de los debates mexicanos de 2012”, en Palabra Clave, núm. 2, vol. 16, Colombia: Universidad de La Sabana.

Echeverría, Martín y Millet, Ana (2013), "El infoentretenimiento en campaña. El caso de los debates presidenciales de 2012", en Carlos Vidal [comp.], XX Anuario de la Comunicación CONEICC, México: CONEICC.

Edelman, Murray (1991), La construcción del espectáculo político, Argentina: Manantial.

Flores-Villar, Alberto (2012), “¿Cuánto influyó la TV en el voto?: caleidoscopio electoral”, en Animal Político. Disponible en: http://www.animalpolitico.com/2012/07/cuantoinfluyo-la-tv-en-el-voto-caleidoscopio-electoral/ [7 de julio de 2012].

Gans, Herbert (2009), “Can popularization help the news media?”, en Barbie Zelizer, The changing faces of journalism. Tabloidization, technology and truthiness, Estados Unidos: Routledge.

Gosselin, Yré (1998), "La comunicación política, cartografía de un campo de investigación y actividades", en Gilles Gauthier, André Gosselin y Jean Mouchon, Comunicación y politica, España: Gedisa.

Igartua, Juan et al. (2007), "El tratamiento informativo de la inmigración en los medios de comunicación españoles. Un análisis de contenido desde la Teoría del Framing”, en Estudios sobre el Mensaje Periodístico, núm. 13, España: Universidad Complutense de Madrid.

Jarman, John (2005), "Political affiliation and presidential debates. A real-time analysis of the effect of the arguments used in the presidential debates", en American Behavioral Scientist, núm. 2, vol. 49, Estados Unidos: Sage.

Jensen, Lars (2012), "Politics as a Game in Danish Newspapers", en Sonderborg papers in linguistics and communication, núm. 2, Dinamarca: University of Southern Denmark.

Johnson-Cartee, Karen (2005), News Narratives and News Framing. Constructing Political Reality. Reino Unido: Rowman and Littlefield. 
Juárez, Julio y Echeverría, Martín (2009), "Cuando la negatividad llega a lo local: publicidad política en tres elecciones estatales en México", en Revista Latina de Comunicación Social, vol. 12, núm. 64, Estados Unidos: Universidad de La Laguna.

Klein, Ulrike (2000), “Tabloidized political coverage in the german Bild-Zeitung”, en Colin Sparks y John Tulloch [comps.], Tabloid Tales. Global Debates over Media Standards, Estados Unidos: Rowman and Littlefield Publishers.

Kraus, Sydney y Davis, Daniel (1981), "Political debates", en Dan Nimmo y Keith Sanders [comps.], Handbook of Political Communication, Inglaterra: Sage.

Lawrence, Regina (2000), "Game-Framing the issues: tracking the strategy frame in public policy news”, en Political Communication, núm. 17, Estados Unidos: Routledge.

McKinney, Mitchell y Carlin, Diana (2004), "Political campaign debates", en Lynda Kaid [comp.], Handbook of Political Communication Research, Estados Unidos: Lawrence Erlbaum Associates.

McQuail, Dennis (1998), La acción de los medios, Argentina: Amorrortu.

McQuail, Dennis (2001), Introducción a la teoría de la comunicación de masas, España: Paidós.

Muñiz, Carlos (2011), "Encuadres noticiosos sobre migración en la prensa digital mexicana. Un análisis de contenido exploratorio desde la teoría del framing”, en Convergencia. Revista de Ciencias Sociales, núm. 55, vol. 18, México: Universidad Autónoma del Estado de México.

Moy, Patricia et al. (2005), "Communication and Citizenship: Mapping the Political Effects of Infotainment”, en Mass Communication and Society, núm. 2, vol. 8, Inglaterra: Routledge.

Patterson, Thomas (1993), Out of Order, Estados Unidos: Vintage.

Reese, Stephen, (2010), "Finding Frames in a Web of Culture. The Case of the War on Terror", en D'Angelo, Paul y Kuypers, Jim [comps.], Doing news framing analysis. Empirical and theoretical perspectives, Estados Unidos: Taylor \& Francis.

Sádaba, Teresa et al. (2007), "Propuesta de sistematización de la teoría del framing para el estudio y praxis de la comunicación política”, en Observatorio (OBS), núm. 2, vol. 6, Portugal: Editora Mundos Sociais.

SEGOB (2013), Padrón Nacional de medios impresos, México: Secretaría de Gobernación.

Semetko, Holli y Valkenburg, Patti (2000), "Framing European politics: a content analysis of press and television news", en Journal of Communication, núm. 1, Estados Unidos: Wiley.

Serpa, Marcelo (2013), Eleições espetaculares: como Hugo Chávez conquistou a Venezuela, Brasil: Contra Capa, Faperj.

Strömbäck, Jesper y Luengo, Óscar (2008), "Polarized pluralist and democratic corporatist models. A comparison of election news coverage in Spain and Sweden", en The International Communication Gazette, núm. 6, vol. 70, Estados Unidos: Sage.

Téllez, Nilsa et al. (2010), "Función discursiva en los debates televisados. Un estudio transcultural de los debates políticos en México, España y Estados Unidos”, en Palabra Clave 13, núm. 2, Colombia: Universidad Javeriana.

Tewksbury, David et al. (2000), "The interaction of news and advocate frames: manipulating audience perceptions of a local public policy issue”, en Journalismy Mass Communication Quarterly, núm. 4, vol. 77, Estados Unidos: Sage. 
Thompson, John (1998), Losmedia y la modernidad. Una teoría de los medios de comunicación, España: Paidós Comunicación.

Torres, Mauricio (2012), “\#Yosoy132 y la cercanía de la elección impulsan 'rating' de segundo debate”, CNN México. Disponible en: http://mexico.cnn.com/ nacional/2012/06/11/yosoy132-y-la-cercania-de-la-eleccion-impulsan-rating-desegundo-debate, [10 de julio de 2012].

Van Dijk, Teun (1990), La noticia como discurso: comprensión, estructura y producción de la información, España: Paidós.

Wyatt, Robert (2000), “Televised Presidential Debates and Public Policy”, en Journalism and Mass Communication Quarterly, núm. 1, vol. 77, Estados Unidos: Sage.

Zhang, Weiwu (2000), "An Interdisciplinay Synthesis of Framing”, ponencia presentada en la Association for Education in Journalism and Mass Communication, agosto, Estados Unidos.

\section{Anexo}

\section{Gráfica 1}

\section{Presencia temporal de los encuadres, primer debate}



Fuente: Elaboración propia. 


\section{Gráfica 2}

\section{Incidencia de los encuadres en los rotativos de la muestra}
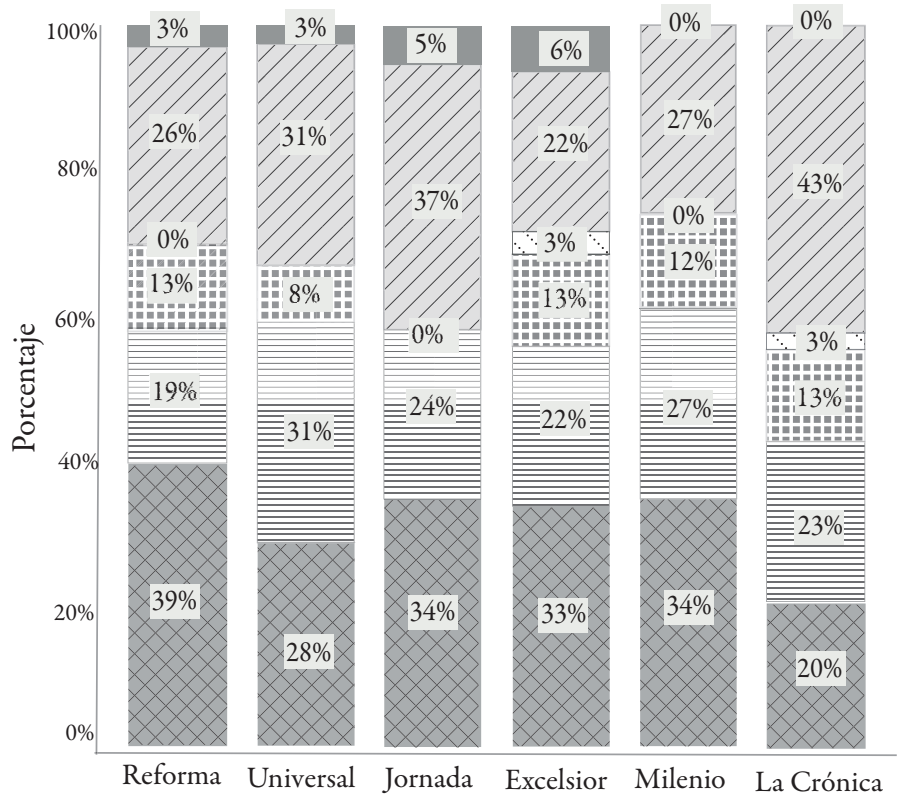

Encuadre

Temas, políticas, ideas

\, Proceso político

$\because$ Liderazgo político

Iit. Drama humano

目 Juego

Estrategia

\section{Rotativo}

Fuente: Elaboración propia. 


\section{Tabla 1}

Presencia y alcance de macro encuadres, encuadres y subencuadres de la cobertura de los debates

\begin{tabular}{|c|c|c|c|c|c|c|}
\hline \multirow{3}{*}{ Encuadres y subencuadres } & \multicolumn{6}{|c|}{ Debate } \\
\hline & \multicolumn{2}{|c|}{$\begin{array}{l}\text { ler } \\
\text { Debate }\end{array}$} & \multicolumn{2}{|c|}{$\begin{array}{l}20 \\
\text { Debate }\end{array}$} & \multicolumn{2}{|c|}{ Total } \\
\hline & $\mathrm{N}$ & $\%$ & $\mathrm{~N}$ & $\%$ & $\mathrm{~N}$ & $\%$ \\
\hline Macro encuadre Política & 87 & $38.0 \%$ & 11 & $18.0 \%$ & 98 & $33.8 \%$ \\
\hline Encuadre Temas, políticas, ideas & 5 & $2.2 \%$ & 4 & $6.6 \%$ & 9 & $3.1 \%$ \\
\hline Posiciones & 5 & $2.2 \%$ & 2 & $3.3 \%$ & 7 & $2.4 \%$ \\
\hline Encuadre Proceso político & 80 & $34.9 \%$ & 6 & $9.8 \%$ & 86 & $29.7 \%$ \\
\hline Organización y regulación formal & 65 & $28.4 \%$ & 2 & $3.3 \%$ & 67 & $23.1 \%$ \\
\hline Acontecimientos informales & 7 & $3.1 \%$ & 4 & $6.6 \%$ & 11 & $3.8 \%$ \\
\hline Eventos significativos & 4 & $1.7 \%$ & 0 & $0.0 \%$ & 4 & $1.4 \%$ \\
\hline Quejas y reclamaciones & 4 & $1.7 \%$ & 0 & $0.0 \%$ & 4 & $1.4 \%$ \\
\hline Cobertura autorreflexiva de medios & 0 & $0.0 \%$ & 2 & $3.3 \%$ & 2 & $0.7 \%$ \\
\hline Encuadre Liderazgo político & 2 & $0.9 \%$ & 1 & $1.6 \%$ & 3 & $1.0 \%$ \\
\hline Liderazgo & 1 & $0.4 \%$ & 1 & $1.6 \%$ & 2 & $0.7 \%$ \\
\hline Ideología y filosofía & 1 & $0.4 \%$ & 0 & $0.0 \%$ & 1 & $0.3 \%$ \\
\hline Macro encuadre Contienda & 142 & $62.0 \%$ & 50 & $82.0 \%$ & 192 & $66.2 \%$ \\
\hline Encuadre Drama humano & 28 & $12.2 \%$ & 2 & $3.3 \%$ & 30 & $10.3 \%$ \\
\hline Acontecimientos chuscos & 24 & $10.5 \%$ & 1 & $1.6 \%$ & 25 & $8.6 \%$ \\
\hline Personalización & 1 & $0.4 \%$ & 1 & $1.6 \%$ & 2 & $0.7 \%$ \\
\hline Revelaciones comprometedoras & 2 & $0.9 \%$ & 0 & $0.0 \%$ & 2 & $0.7 \%$ \\
\hline Interés humano & 1 & $0.4 \%$ & 0 & $0.0 \%$ & 1 & $0.3 \%$ \\
\hline Encuadre Juego & 49 & $21.4 \%$ & 19 & $31.1 \%$ & 68 & $23.4 \%$ \\
\hline
\end{tabular}




\begin{tabular}{lllllll} 
Ganar/Perder & 21 & $9.2 \%$ & 5 & $8.2 \%$ & 26 & $9.0 \%$ \\
Marcadores & 14 & $6.1 \%$ & 8 & $13.1 \%$ & 22 & $7.6 \%$ \\
Deporte, guerra, competencia & 13 & $5.7 \%$ & 6 & $9.8 \%$ & 19 & $6.6 \%$ \\
Posibles resultados & 1 & $0.4 \%$ & 0 & $0.0 \%$ & 1 & $0.3 \%$ \\
\hline Encuadre Estrategia & 65 & $28.4 \%$ & 29 & $47.5 \%$ & 94 & $32.4 \%$ \\
Conflicto dentro de campo político & 36 & $15.7 \%$ & 22 & $36.1 \%$ & 58 & $20.0 \%$ \\
Conflicto fuera del campo político & 15 & $6.6 \%$ & 3 & $4.9 \%$ & 18 & $6.2 \%$ \\
Tácticas o estrategias & 6 & $2.6 \%$ & 1 & $1.6 \%$ & 7 & $2.4 \%$ \\
Aclamaciones & 4 & $1.7 \%$ & 2 & $3.3 \%$ & 6 & $2.1 \%$ \\
Controversias & 3 & $1.3 \%$ & 0 & $0.0 \%$ & 3 & $1.0 \%$ \\
Alianzas & 1 & $0.4 \%$ & 1 & $1.6 \%$ & 2 & $0.7 \%$ \\
\hline Total & 229 & $79.0 \%$ & 61 & $21.0 \%$ & 290 & $100.0 \%$ \\
\hline
\end{tabular}

Fuente: Elaboración propia.

Tabla 2

\section{Aplicación de macro encuadres a determinados grupos y actores}

\begin{tabular}{llllll}
\hline \multirow{2}{*}{ Actores } & \multicolumn{7}{l}{ Macro Encuadre } & & \\
\cline { 2 - 6 } & \multicolumn{2}{l}{ Política } & Contienda & Rango \\
\cline { 2 - 6 } & $\mathrm{N}$ & $\%$ & $\mathrm{~N}$ & $\%$ & $\mathrm{~N}$ \\
\hline Autoridad electoral (INE, Tribunal) & 45 & $76 \%$ & 14 & $24 \%$ & 31 \\
Candidatos & & & & & \\
\hline Josefina Vázquez Mota & 3 & $8 \%$ & 33 & $92 \%$ & 30 \\
Enrique Peña Nieto & 5 & $17 \%$ & 24 & $83 \%$ & 19 \\
Andrés Manuel López Obrador & 3 & $11 \%$ & 24 & $89 \%$ & 21 \\
Gabriel Quadri de la Torre & 1 & $4 \%$ & 22 & $96 \%$ & 21 \\
Candidatos en general & 4 & $14 \%$ & 24 & $86 \%$ & 20 \\
Subtotal & 16 & $11 \%$ & 127 & $89 \%$ & 111 \\
\hline
\end{tabular}




\begin{tabular}{llllll}
\hline Partidos y equipos de campaña & & & & & \\
\hline Miembros del PRD & 15 & $56 \%$ & 12 & $44 \%$ & 3 \\
Miembros del PRI & 5 & $24 \%$ & 16 & $76 \%$ & 11 \\
Miembros del PAN & 5 & $31 \%$ & 11 & $69 \%$ & 6 \\
Campaña PRI & 6 & $55 \%$ & 5 & $45 \%$ & -1 \\
Campaña PRD & 3 & $60 \%$ & 2 & $40 \%$ & -1 \\
Miembros de Nueva Alianza & 0 & $0 \%$ & 4 & $100 \%$ & 4 \\
Campaña PAN & 1 & $25 \%$ & 3 & $75 \%$ & 2 \\
Subtotal & 35 & $40 \%$ & 53 & $60 \%$ & 18 \\
\hline Miembros de la sociedad civil & & & & & \\
\hline Ciudadanos & 9 & $23 \%$ & 30 & $77 \%$ & 21 \\
Expertos de universidades o centros de & 7 & $25 \%$ & 21 & $75 \%$ & \\
investigación & & & & & 14 \\
Cámaras y organismos empresariales & 4 & $44 \%$ & 5 & $56 \%$ & 1 \\
Organismos de la sociedad civil & 2 & $40 \%$ & 3 & $60 \%$ & 1 \\
Iglesia católica & 1 & $33 \%$ & 2 & $67 \%$ & 1 \\
Subtotal & 23 & $27 \%$ & 61 & $73 \%$ & 38 \\
\hline
\end{tabular}

Fuente: Elaboración propia.

Martín Echeverría. Doctor en Comunicación y Cultura. Profesor Investigador del Instituto de Ciencias de Gobierno y Desarrollo Estratégico, Universidad Autónoma de Puebla. Líneas de investigación: infoentretenimiento en la cobertura periodística de las elecciones y el desempeño de los debates presidenciales. Publicaciones recientes: "Representaciones de la pobreza en contextos de crisis. Un ejercicio desde el análisis crítico del discurso", en Revista Signo y Pensamiento, vol. 33 (2014); La opinión pública en la era de la información. Propuesta Teórico-Metodológica para su análisis en México (2014); "Debates presidenciales y calidad de la democracia. Análisis empírico normativo de los debates mexicanos 2012", en Revista Palabra Clave, vol. 16 (2013).

Recepción: 11 de enero de 2016.

Aprobación: 9 de septiembre de 2016. 